\title{
TRAUMA-INDUCED ACINETOBACTER LWOFFI ENDOPHTHALMITIS WITH MULTI-ORGANISM RECURRENCE: STRATEGIES WITH INTRAVITREAL TREATMENT
}

\author{
P. MARK CRAWFORD, JR, MANDI D. CONWAY and GHOLAM A. PEYMAN \\ New Orleans, Louisiana
}

\begin{abstract}
SUMMARY
Endophthalmitis and its treatment are challenging, controversial subjects. We report here a patient whose recurrent endophthalmitis required several modes of treatment.
\end{abstract}

\section{CASE REPORT}

A 27-year-old white man sustained a corneal laceration and traumatic cataract by an unknown mechanism after a fall on a ship. One day after primary corneal repair and cataract removal, scattered vitreous cells were noted. The patient was given intravenous gentamicin and cefazolin, and topical ciprofloxacin and steroids. By postoperative day 3 , the inflammation was deemed stable, and the patient was discharged on oral antibiotics and topical steroids and antibiotics.

Two days later, the patient was referred to the LSU Eye Center. Vitreous cells were again detected, and low-grade endophthalmitis was suspected. A computed tomography (CT) scan of the eye and orbit revealed no radiopaque foreign body. The eye was tapped and injected intravitreally with amikacin $(200 \mu \mathrm{g})$, clindamycin $(200 \mu \mathrm{g})$ and dexamethasone (1 mg).

The intravitreal inflammation increased over 4 days, and the patient underwent a pars plana vitrectomy, capsulectomy, reinforcement of corneal sutures, and intravitreal amphotericin B $(5 \mu \mathrm{g})$ and dexamethasone $(1 \mathrm{mg})$. The infusion fluid contained gentamicin $(4 \mu \mathrm{g} / \mathrm{ml})$ and dexamethasone $(64 \mu \mathrm{g} / \mathrm{ml})$. The patient was discharged on topical natamycin,

From: LSU Eye Center, Louisiana State University Medical Center School of Medicine, New Orleans, Louisiana, USA.

Correspondence: Dr Gholam A. Peyman, LSU Eye Center, 2020 Gravier Street, Suite B, New Orleans, LA 70112-2234, USA. Tel: +1 (504) 568-6700 ext 341. Fax: +1 (504) 568-6193. tobramycin and dexamethasone, and prednisone acetate. Cultures from the initial intravitreal tap grew Acinetobacter lwoffi, a rare cause of endopthalmitis. ${ }^{1-3}$

The eye reached a visual acuity of $20 / 25$. Over several months, a mild anterior chamber inflammation persisted with a quiet vitreous. The patient had a corneal suture removed and 4 days later began complaining of increased irritation. Vitreous cells $(2+)$ were noted and another vitreous tap and injection were performed. Intravitreal tobramycin $(200 \mu \mathrm{g})$, imipenem $(80 \mu \mathrm{g})$ and dexamethasone $(500$ $\mu \mathrm{g})$ were administered. The following day, a medically non-responsive pressure rise was treated by a paracentesis. Several hours later there was a hypopyon, and no view of the retina.

A repeat pars plana vitrectomy and intravitreal injection of antibiotics were performed at one-tenth the doses recommended in non-vitrectomised eyes (clindamycin, $50 \mu \mathrm{g}$; gentamicin, $50 \mu \mathrm{g}$; and dexamethasone, $1 \mathrm{mg}$ ). Infusion fluid additives were gentamicin $(8 \mu \mathrm{g} / \mathrm{ml})$ and vancomycin $(20 \mu \mathrm{g} / \mathrm{ml})$ in the first $400 \mathrm{~cm}^{3}$ and clindamycin $(9 \mu \mathrm{g} / \mathrm{ml})$ and gentamicin $(8 \mu \mathrm{g} / \mathrm{ml})$ in the next $200 \mathrm{~cm}^{3}$.

The cultures from the second vitrectomy grew multiple organisms: Pseudomonas maltophilia, Spingobacterium multibovum, Streptomyces sp., an aerobic non-spore-forming Gram-positive rod, and Staph-coagulase negative.

Over the next 3 weeks the eye had a mild, persistent anterior chamber inflammation. The patient complained of unrelenting pain and developed a hypopyon and vitreous cells. The eye was again tapped and injected intravitreally with vancomycin $(50 \mu \mathrm{g})$, amphotericin $\mathrm{B}(5 \mu \mathrm{g})$ and dexamethasone $(1 \mathrm{mg})$. Cultures were negative. Because of the continuous pain in the superior fornix, an orbital foreign body or abscess was suspected. A B- 
scan and repeat CT scan were both negative for a metallic foreign body but suspicious for an orbital abscess. On orbital exploration, no orbital abscess or foreign body was found.

Family members disclosed a possible explanation of the patient's recurrent infections. He was discovered placing injectable novocaine (given to him by a dentist friend) into his topical antibiotic bottle. He reused the same syringe, rinsing it with tap water between withdrawals from the anaesthetic vial. Probably, he contaminated his eye drops with multiple unusual water-borne organisms ${ }^{4}$ and infected his eye through the corneal suture tracts.

All corneal sutures were removed. The patient returned 1 month later with moderate pain and vitreous cells and was tapped and injected again with intravitreal vancomycin $(50 \mu \mathrm{g})$, clindamycin $(50 \mu \mathrm{g})$ and dexamethasone $(500 \mu \mathrm{g})$. The eye responded well, and the patient's course finally began to improve. Remarkably, his visual acuity with a hard contact lens was 20/25. He was considering refractive surgery for his irregular astigmatism until he developed an epiretinal membrane, decreasing his visual acuity to $20 / 80$, and then elected to have no more surgery.

\section{DISCUSSION}

This patient not only had a rare organism, Acinetobacter lwoff, ${ }^{1-3}$ isolated from the initial infection, but also had multiple recurrences of endophthalmitis, probably from self-contamination as a result of using non-sterile antibiotic drops.

This case illustrates the need for research on the causes of multiple recurrences of endophthalmitis.

Supported in part by US Public Health Service grants EY07541 and EY02377 from the National Eye Institute, National Institutes of Health, Bethesda, MD, and by an unrestricted departmental grant from Research to Prevent Blindness, New York, NY.

Key words: Acinetobacter lwoffi, Endophthalmitis, Recurrent infection, Trauma

\section{REFERENCES}

1. Melki TDS, Sramek SJ. Trauma-induced Acinetobacter lwoffi endophthalmitis [letter]. Am J Ophthalmol 1992;113:598-9.

2. Peyman GA, Raichand M, Bennett TO. Management of endophthalmitis with pars plana vitrectomy. Br J Ophthalmol 1980;64:472-5.

3. Mark DB, Gaynon MW. Trauma-induced endophthalmitis caused by Acinetobacter anitratus. Br J Ophthalmol 1983;67:124-6.

4. Mandell GL, Douglas RG Jr, Bennett JE (eds). Principles and practice of infectious diseases. 3rd ed. vol 2. New York: Churchill Livingstone, 1990:1692, 1790. 